NBER WORKING PAPER SERIES

\title{
SOCIALLY RESPONSIBLE INVESTMENT IN JAPANESE PENSIONS
}

\author{
Henry Hongbo Jin \\ Olivia S. Mitchell \\ John Piggott \\ Working Paper 11747 \\ http://www.nber.org/papers/w11747 \\ NATIONAL BUREAU OF ECONOMIC RESEARCH \\ 1050 Massachusetts Avenue \\ Cambridge, MA 02138 \\ November 2005
}

Jin is a Research Associate, Centre for Pensions and Superannuation, University of New South Wales. Mitchell is a Research Associate at the NBER and International Foundation of Employee Benefit Plans Professor of Insurance and Risk Management, and Executive Director of the Pension Research Council, at the Wharton School of the University of Pennsylvania. Piggott is Professor of Economics and Director of the Centre for Pensions and Superannuation, University of New South Wales. Funding for this research was provided by the Economic and Social Research Institute, Cabinet Level, Government of Japan, the Pension Research Council, and the Australian Research Council. The authors thank Morningstar and the Securities Institute Research Centre of Australia (SIRCA) for valuable data resources, and John Evans, Akira Kawaguchi, Kiyohiko Nishimura, Adrian Pagan, Makato Saito, Kenji Sekine, Susan Thorp, Emil Valdez, and participants at the 2005 ESRI Collaboration meetings in Tokyo for useful research collaboration, advice, and comments. Data were kindly supplied by Securities Industry Research Centre of Asia-Pacific (SIRCA) on behalf of Reuters. The authors retain full responsibility for opinions and any errors. The views expressed herein are those of the author(s) and do not necessarily reflect the views of the National Bureau of Economic Research.

(C)2005 by Henry Hongbo Jin, Olivia S. Mitchell, and John Piggott. All rights reserved. Short sections of text, not to exceed two paragraphs, may be quoted without explicit permission provided that full credit, including (C) notice, is given to the source. 
Socially Responsible Investment in Japanese Pensions

Henry Hongbo Jin, Olivia S. Mitchell, and John Piggott

NBER Working Paper No. 11747

November 2005

JEL No. G11, G20, G23

\section{ABSTRACT}

As the level of retirement-related assets has grown, so too has public and private interest in so-called "Socially Responsible Investment" (SRI), an investment strategy that employs criteria other than the usual financial risk and return factors when selecting firms in which to invest. This study evaluates whether SRI indexes would alter portfolio risk and return patterns for the new defined contribution pension plans currently on offer in Japan. We conclude that SRI funds can be included as an option, albeit with some cost; consequently, mandatory investment in SRI portfolios cannot reasonably be justified.

Henry Hongho Jin

Centre for Pensions and Superannuation

University of New South Wales

Sydney 2052, Australia

hongbo.jin@unsw.edu.au

Olivia S. Mitchell

Department of Insurance and Risk Management

Wharton School

University of Pennsylvania

Philadelphia, PA 19104

and NBER

mitchelo@wharton.upenn.edu

John Piggott

School of Economics

University of New South Wales

Sydney 2052, Australia

j.piggott@unsw.edu.au 


\section{Socially Responsible Investment in Japanese Pensions}

It is sometimes suggested that socially-targeted investment objectives may overlap with individual investment strategies for retirement saving products, by mediating the process of social targeting through individual preferences and the capital market. This study examines the pros and cons of socially responsible investment (SRI) criteria for pension investors in Japan, to develop a better understanding of how such criteria might be introduced into investment strategies for pension plans, and what the implications of SRI rules might be on investment performance.

There are many different definitions of SRI both in the West ${ }^{1}$ and in the growing Asian funded pension market. ${ }^{2}$ Defining what constitutes SRI is difficult, since criteria selected to target "in favor of" or "against” companies are often subjective and vary from one group, individual, and nation, to another. In addition, formulating benchmarks and evaluating performance for such socially targeted investments is a complex, involved, and sometimes costly objective process.

In the Japanese case, interest in SRI rules is just beginning to evolve, although questions of corporate governance have a longer history (Hiraki et al 2003). As indicated by recent amendments to the methods used for investment of Japanese Postal Saving System (JPSS) assets, fiduciaries are gradually moving JPSS investment allocations away from social targeting toward

\footnotetext{
${ }^{1}$ For example, the Social Investment Forum (http://www.socialinvest.org/Areas/SRIGuide/) defines SRI as "[i]ntegrating personal values and societal concerns with investment decisions ... [it]considers both the investor's financial needs and an investment's impact on society. With SRI, you can put your money to work to build a better tomorrow while earning competitive returns today.”

${ }^{2}$ A discussion of SRI activity in Asia is provided by ASRIA [2002] who argues that "sustainable and Responsible Investment (SRI), also known as Socially Responsible Investment, is investment which allows investors to take into account wider concerns, such as social justice,
} 
more conventional financial criteria, in part because of concerns that sub-optimal investment decisions were made in the past [Lincoln, 2001]. Nevertheless, many Japanese intellectuals, business leaders, and politicians remain convinced that socially targeted investment of some kind will be important for the future of the nation [Nishimura and Saiko, 2003].

The pension asset market in Japan is substantial. In March 2005, the Bank of Japan reported total pension fund assets at JPY 93.6 trillion. ${ }^{3}$ Since 2001, Japan has been encouraging the development of defined contribution (DC) plans, and there is currently debate over whether SRI portfolios should be offered in these plans. While Japan SRI portfolios are quite small, they are likely to grow rapidly in coming years. In what follows, therefore, we begin with a discussion of the introduction of SRI developments in Japan and a comparison between the two most important SRI indices marketed in Japan, namely Morningstar SRI and FTSE4Good. The following section compares the performance four hypothetical SRI funds derived from these two SRI indices with that of standard Japanese stock market indices. Then we discuss our methods to adjust the survivor bias that might be introduced in backward looking analysis.

We find that the hypothetical SRI portfolio performance is not significantly different from that of the corresponding hypothetical market portfolio. Subsequently we turn to the question of whether an SRI designation contains market information in its own right regardless of the weights attaching on each SRI stock, and again we use hypothetical portfolios to address this question in an econometric approach. A final section concludes.

economic development, peace or a healthy environment, as well as conventional financial considerations."

${ }^{3}$ This compares with USD7.3 trillion in US pension funds [Bank of Japan 2005] 


\section{Social Responsible Investment in Japan}

Few English-language papers discuss the topic of SRI funds in Japan (c.f. ASRIA , [2003], Kawamura [2002, 2004], and Solomon et al. [2004]), and while they are informative on the newly developing SRI movement in Japan, they offer little in the way of technical analysis of the performance of Japanese SRI funds. To this, we turn next.

Japanese SRI Indices. There are currently two established SRI indices and around 10 SRI funds in Japan, most of which are environmentally-focused. The first SRI index was introduced by Morningstar in May 2003; in September of 2004, FTSE launched its FTSE4Good index for Japan. Both indices focus on socially responsible corporations in Japan. Our approach in addressing SRI performance in Japan is to focus on these two SRI indices, which we compare against key market indices. Because the indexes were established only recently, we also take a backward look at the performance of the SRI indices (from Jan 1997 to Feb 2005). The time period used is, in part, imposed by data availability; but also SRI advocates argue that it is only in the last few years that SRI principles have been explicitly and consistently adhered to by responsible firms. For this reason, they argue that a longer time period may in fact confuse the analysis.

Understanding Japanese SRI Indexes. Our comparison relies on the components of the Morningstar-SRIJapan and the FTSE4Good indices as of September 2004. In that month, Morningstar reported 150 stocks in its SRI index, whereas there were 166 in the newly launched FTSE4Good set. Taken as a whole, 233 Japanese stocks were included in SRI Japan indices, but only 83 stocks were common to both indices. As indicated in Table 1, if we regarded these 233 Japanese stocks as the possible universe of socially responsible Japanese corporations, the FTSE4Good index includes 71\% of the SRI stocks, and Morningstar includes $64 \%$ of the set. 
Table 1 here

Our further analysis also indicates some rather interesting differences between the two SRI-Japan indices, both in terms of the companies that are included and also in their weights. One striking finding is that the two indices differ strongly with regard to the top ten stocks included (Table 2). The top 10 group represents about $40 \%$ and $35 \%$ of the index weights for the FTSE4Good Japan and Morningstar SRI Japan indices, respectively. Most prominently, FTSE4Good includes the two large motor companies Toyota and Honda, while these are omitted by Morningstar. Conversely, Morningstar includes the Mizuho Financial Group and Takeda Chemical, but these are excluded by FTSE4Good.

Table 2 here

It is also interesting that the weights of the eight stocks that both indices list in their top 10 differ markedly. Thus, Toyota and Honda represent about 15\% of the FTSE4Good Japan index, while Mizuho Financial Group and Takeda account for about 9\% of the Morningstar index. Although both indices used free floating market capitalization as the basis of their index weights, it is apparent that important differences remain in the top 10 stock rankings for the two SRI indices. As another example, NTT is ranked first in the Morningstar SRI, representing $5.31 \%$ of the portfolio, but that firm ranks only $9^{\text {th }}$ by FTSE4GOOD, representing $2.40 \%$ of the mix.

Why do these two SRI portfolios differ so substantially? First, the two rating firms report that they draw from a different underlying stock universe in developing their indices. Elements in the FTSE4Good Japan list are selected from the FTSEJapan list. By contrast, Morningstar's SRI stocks are selected from 3600 listed Japanese companies. Second, the stock screening processes used by the two SRI groups are unlikely to be identical. This is because FTSE 
indicates that it relies more heavily on international SRI conventions, ${ }^{4}$ while Morningstar appears to adhere to more localized criteria.

In evaluating the performance of these two indexes, we are faced with the problem that the firms included in the two sets may have been influenced by "cherry-picking:" that is, the particular firms selected might have been influenced not only by positive screening reports, but also because of positive past returns. If this were the case, a positive retrospective statistical relationship between social and financial performance could be contaminated by selection bias. This problem is difficult to solve. The most persuasive study would have to compare the future performance of the SRI indices selected years earlier, against future market experiences.

\section{A Retrospective Assessment of Japanese SRI Performance}

In the meanwhile, we believe that a retrospective analysis does provide useful information. Specifically, we compare the financial performance of several alternative Japanese SRI portfolios against the major Japanese stock index TOPIX. ${ }^{5}$ A top 10 constituent portfolio and a full index portfolio were constructed respectively for Morning Star SRI Japan (MS) and FTSE4GOOD Japan (F4G) according to their launching weights as of in May 2003 and Sep 2004. The portfolios then were rebalanced monthly using their initial weights constantly.

Results of the retrospective analysis appear in Figure 1. One striking finding is that all four SRI portfolios outperformed the TOPIX index over the 98-month sample period (Jan 1997 Dec 2003). Indeed, it is rather remarkable that, while the TOPIX lost about $20 \%$ in this span, all of the alternatively-weighted SRI portfolios achieved positive returns. Figure 1 indicates that

\footnotetext{
${ }^{4}$ See http://www.morningstar.co.jp/sri/about.htm and http://www.ftse.com/ftse4good/news/FTSE4Good_Criteria_Development_Report_2004.pdf. Morningstar SRI was developed by the Public Resource Centre and Professor Kanji Tanimoto of Hitotsubashi University.
} 
FTSE portfolios gained above 60\% while Morningstar SRI hypothetical funds achieved over $50 \%$ total return in a 8-year recession period.

Figure 1 here

Of course, higher returns may come with higher risks, so next we ask whether holding a Japanese SRI portfolio might have reaped higher performance in exchange for risk. Table 3 shows that the SRI portfolios we have devised were generally not significantly more volatile than the Japanese market indices, at least over the period from 1997-2005. For example, the annualized monthly volatilities were around $16 \%$ and $17 \%$ for the two responsible full-index funds, just slightly below or equal to that of the TOPIX (17\%). Further, as the entire stock market was moving, none of the funds appeared more volatile than the market as a whole, as indicated by the fact that all the betas of SRI portfolios are below one.

Table 3 here

To summarize, these results indicate that the Japanese SRI portfolios constructed using a constant-weighting method with the Morningstar and FTSE4Good set of stocks outperformed the market averages using TOPIX over the 98 months ending in Feb 2005, without taking on additional market risk. Yet caveats remain. First, few years of data are available to track SRI fund performance. Second, it must be recognized that because the SRI indices are quite new in Japan, retrospective analysis runs the risk of cherry-picking and other bias. Additional years of data will be required to generate firmer conclusions.

\section{SRI versus Alternative Benchmarks}

Thus far we have used TOPIX as the main Japanese benchmark against which we compare various hypothetical SRI portfolios derived from two key SRI indices in Japan. But a

\footnotetext{
${ }^{5}$ TOPIX is selected as a proxy for the Japanese stock market because it is a market-cap weighted
} 
problem with this is that the TOPIX is a dynamically-changing index, whereas our analyses of SRI stock portfolios are of necessity backward-looking. Thus potential benefits of a hypothetical SRI portfolio are easily conflated with the benefits of hindsight. We have already mentioned cherry-picking, but there is also the broader issue that performance of the TOPIX index reflects corporate failures, mergers, and acquisitions, which a backward-looking approach does not take into account.

Accordingly, we seek to correct for this inconsistency by developing a hypothetical market portfolio of our own for the purpose of comparing it with alternative SRI portfolios. This market portfolio, for convenience labeled the JMP index, is constructed from the Nikkei 500 and the FTSE Japan index, ${ }^{6}$ augmented to include those Morningstar SRI stocks not included in either index, for a total of 563 stocks. We then consider these as a 'universe' of current Japanese stocks, from which the SRI stocks may be drawn. Next we construct what we call a "JMP SRI index" (JMP-SRI), which includes all the stocks in both the Japanese MS SRI and the FTSE4Good indices. Altogether, 233 SRI stocks are included, almost all of them drawn from the two market Japan portfolios.

To construct both portfolios, we use dynamic market capitalization as weights, rebalance monthly, and, consistent with our earlier analysis, we exclude dividends. ${ }^{7}$ Both the JMP and JMP-SRI indices include only stocks which existed in September 2004, and for which at least two years of data are available. Both are thus subject to symmetric survivor bias. In our

index, although it is not as popular as the NIKKEI225.

6 The number of stocks within the FTSE Japan index is about 480 over time; as of 15 March 2005 there were 479 stocks included.

${ }^{7}$ In Japan, the size of dividend change has been found to have a strong positive effect on the magnitude of the excess returns (Kato et al 2002). However, the dividend effects show no significant differences between the SRI stock group and non-SRI stocks; detailed regression results available on request. 
comparison analysis, we therefore implicitly assume that this bias has similar effects on both portfolios.

Figure 2 plots the price performance of the JMP and JMP-SRI funds over our sample period; for comparison, we also reproduce the TOPIX index line. The results are striking: the JMP and the JMP-SRI portfolios track each other closely over the sample period, while the TOPIX return line falls significantly below these two. In other words, the apparently superior performance of the SRI portfolio detected in the previous section when compared to the TOPIX evaporates when we use our alternative all-Japan market benchmark.

Figure 2 here

We also note that the combined SRI portfolio substantially underperformed the various hypothetical SRI portfolios such as MS150 or F4G166. A possible explanation could be the different weights attached to various stocks and the rebalancing strategies. The constituent weights of firms in both SRI index funds are not precisely consistent with their market capitalization due to liquidity, investability and other possible considerations. $^{8}$

\section{The Information Value of an SRI Flag in Japan}

Our last finding raises the question of whether new information is provided by knowing that a firm has been selected to be a member of a SRI portfolio. To investigate this question, we pool the data across both time and stocks in order to learn whether any information is carried by an SRI designation on a stock-by-stock basis, regardless of the weights. ${ }^{9}$

Accordingly, Model 1 compares stock-by-stock performance with the overall market represented by the JMP portfolio and asks whether an SRI flag adds statistical explanatory power.

\footnotetext{
${ }^{8}$ Morningstar adjusts the market capitalization weights on the basis of liquidity considerations, while FTSE adopts the concept of "investability."
} 
Specifically, we regress the excess return of each JMP stock over the 98 months for which we have data, on the monthly excess return of the market and an indicator which indicates whether a stock has been designated as SRI-admissible in either the MS-SRI or FTSE4Good set. The hypothesis is that if an SRI flag contained important market information, the flag would be significant. The regression equation for model 1 is thus given by:

$$
r_{i, t}-r_{f, t}=\alpha+\beta\left(r_{J M P, t}-r_{f, t}\right)+\gamma \cdot S R I_{i}+u_{1}
$$

where $r_{i, t}-r_{f, t}$ is the excess return of $\mathrm{i}^{\text {th }}$ stock in $\mathrm{t}^{\text {th }}$ month over the corresponding risk free return; $r_{J M P, t}-r_{f, t}$ gives the excess return of our JMP hypothetical portfolio over the risk free return in $\mathrm{t}^{\text {th }}$ month; and $S R I_{i}$ is the dummy variable representing the life-time SRI label ${ }^{10}$ for $\mathrm{i}^{\text {th }}$ stock. In a second formulation, we add controls for market cap bias ${ }^{11}$ and investment style bias ${ }^{12}$ (Model 2):

$$
r_{i, t}-r_{f, t}=\alpha+\beta\left(r_{J M P, t}-r_{f, t}\right)+\gamma \cdot S R I_{i}+\psi \cdot C A P_{i, t}+\omega \cdot P B_{i, t}+u_{2}
$$

where $C A P_{i, t}$ represents the market cap of $\mathrm{i}^{\text {th }}$ stock in $\mathrm{t}^{\text {th }}$ month; and $P B_{i, t}$ represents the price to book value ratio of $\mathrm{i}^{\text {th }}$ stock in $\mathrm{t}^{\text {th }}$ month.

The two models above are designed to reveal the ability of SRI flag to carry additional alpha. One step further, one might also be interested in finding the potential information of risk. Model 3 and 4 add to the first two models an additional interaction term $\left(r_{J M P, t}-r_{f, t}\right) \times S R I_{i}$, so

\footnotetext{
${ }^{9}$ Large-cap stocks often dominate the overall performance of a portfolio, and therefore the equally-weighted approach may be a good compromise to control for weighting bias.

${ }^{10}$ We also tried the monthly SRI flags as possible candidates but they are statistically insignificant.

${ }^{11}$ Small company effects and fund size effects are suggested by Luck et al. [1992], Wood [1992] and Gregory et al. [1997].

${ }^{12}$ See also Bauer et al. [2002] for more detail on investment style bias in SRI analysis.
} 
that the impact of SRI flag on beta can be studied. Furthermore, a pre- and post- comparison is also carried out around the time when the first SRI index was launched in May 2003.

Econometric estimates appear in Table 4. Model 1 indicates that the SRI flag is now not significantly different from zero for the period prior to the initial launch of the SRI index. After that, the SRI flag has a negative impact on financial performance. We also expand the regression models to take account of differences in cap size and price-to-book value ratios. Here we again find a negative but slightly reduced impact when controlling on market capitalization bias and growth/value style bias in Model 2. In Models 3 and 4, we evaluate the impact on intercept (alpha) and also the potential information on the slope (beta). Interestingly, the negative impact of alpha is no longer statistically significant, but the betas of SRI stocks are now significantly lower than the average of non SRI stocks.

\section{Table 4 here}

From a statistical perspective, then, we conclude that the SRI flag is not informative about a stock's performance before the concept of SRI was officially introduced to Japan; that is, ex ante, SRI stocks did not perform better. By contrast, the post-launch evidence suggests that holding a SRI portfolio might involve financial sacrifice ${ }^{13}$ vis a vis a diversified market portfolio. This is of course consistent with conventional portfolio theory [Rudd 1981 and Chami et al 2002], although others (for example Evans and Guido [2004]) find no underperformance in a global context. Other explanations also exist for our results. Bauer, Koedijk and Otten [2005] and Bauer, Otten and Rad [2005], for example, provide evidence that SRI funds tend to perform poorly in their early years, when going through what they term a "learning effect" or "catching up phase”, and subsequently perform much better. As well, returns might be reduced because of 
the cost of compliance associated with SRI accreditation. Our results also suggest that Japanese SRI companies are risk adverse ${ }^{14}$ in their financial decision making and market performance. A possible explanation for this is that firms adhering to SRI principles, or striving to meet SRI criteria, take less risk and have a generally more conservative management style than others.

\section{Conclusions and Implications}

We examine socially responsible investments in Japan, focusing on possible roles for SRI in pension portfolios. Because the two key indexes in Japan, the Morningstar-SRI Japan and FTSE4Good Japan indexes, were established only recently, we opt first to take a backward look at the performance of these indices for the eight years between December 1996 and Feb 2005. Looking backward, we find that these SRI portfolios outperformed the TOPIX stock market index over the sample period, quite an accomplishment since the market as a whole lost about $20 \%$ over the period. Another interesting finding is that the SRI portfolios we examine were not significantly more volatile than the TOPIX index. The short time span available for analysis, however, is a concern, particularly because some of the SRI portfolios underperformed the market immediately after the introduction of the Morningstar SRI index. When we look forward over the short period since the establishment of the funds, results suggest a risk-adjusted return somewhat below the market.

The implication is that Japanese historical evidence offers no support for the position that Japanese pension participants would benefit from being required to invest in firms included on SRI lists. At the same time, we also find no strong reason to preclude Japanese pension

\footnotetext{
${ }^{13}$ Risk-adjusted underperformance is estimated at around 18 basis points per month (2.2\% p.a.) below the market average. See Appendix A for more detail.

${ }^{14}$ The cap-weighted SRI portfolio had beta of 0.92 with JMP hypothetical market portfolio as the benchmark in a post launch analysis. Further, the volatility of SRI portfolio was about 74 basis points lower than that of the proxy of market.
} 
participants from investing part of their pension assets in an SRI-based portfolio if they so desire, provided participants are made aware of the potential costs of this decision. ${ }^{15}$ To this end, the experience of one of the largest US pension plans may be instructive, that of TIAA-CREF, a \$325B (US) retirement system covering faculty and staff in higher educational and research institutions. This large and influential pension system offers pension participants several investment choices, among them a Social Choice Account which currently manages more than $\$ 6$ billion (US) in assets. Individual employees and retirees may elect to invest in this, or several other funds, as they see fit.

SRI funds in Japan are still quite new, but we anticipate that they are likely to grow in popularity as pension asset pools develop and as individual employees are granted more influence over their pension asset allocation decisions. Accordingly, our analysis should be of use in demonstrating how performance measures for socially-targeted investment funds might be constructed and evaluated in the Japanese context. Additional research is required to evaluate whether SRI funds should be expected to play a different role in defined benefit versus defined contribution pensions, and also whether public sector versus corporate pension funds should take a different stance regarding SRI policies. Further analysis is also required on how pension supervisors and regulators might respond if socially-targeted investments in pension funds were to become very popular in Japan. As pension asset pools become increasingly important in financing the retirement benefits of a growing elderly population, clearer policies will be needed defining when and how pensions might be permitted to opt for SRI investments.

\footnotetext{
${ }^{15}$ For a recent analysis of ill-advised portfolio choices by pension plan participants, see Douglass et al. [2004].
} 


\section{References}

ASRIA. 2002. SRI and Pensions in Asia. ASRIA Monograph. October.

ASRIA. 2003. Foreign versus Local: The Debate About SRI Priorities in Japan. ASRIA Monograph. October. www.asria.org/publications/lib/japan/japan_perspective_colour.pdf

Bauer, R., Koedijk, K., Otten, R., 2005. International evidence on ethical mutual fund performance and investment style. Journal of Banking and Finance 29, 1751-1767.

Bauer, R., Otten, R., Rad, A.T., 2005. Ethical investment in Australia: is there a financial penalty? Pacific Basin Finance Journal. Forthcoming.

Chami, R, T.F. Cosimano, and C. Fullenkamp. 2002. Managing Ethical Risk: How Investing in Ethics Adds Value Journal of Banking Finance 26: 1697-1718.

Douglass, J., Owen Wu, and William Ziembra. 2004. Stock Ownership Decisions in Defined Contribution Pension Plans. Journal of Portfolio Management 30 Summer: 92-100.

Evans J, and R. Guido. 2004, A Review of Returns on Securities Selected for their 'Sustainable'Characteristics. Working Paper, University of New South Wales.

Gregory, Matatko and Luther. 1997. Ethical Unit Trust Financial Performance: Small Company Effects and Fund Size Effects. Journal of Business Finance \& Accounting. 24 (5).

Hiraki, T., Inoue, H., Ito,A., Kuroki, F., and Masuda,H., 2003. Corporate Governance and firm value in Japan: Evidence from 1985 to 1998. Pacific-Basin Finance Journal 11, 239-265

Kato,H.,K., Loewenstein,U., and Tsay,Wenyuh., 2002. Dividend Policy, Cash Flow, and Investment in Japan. Pacific-Basin Finance Journal. 10, 443-473

Kawamura, M. 2002. How Socially Responsible Investment Could Redefine Corporate Excellence in the $21^{\text {st }}$ Century. NLI Research Institute, No 160. Tokyo, Japan.

Kawamura, M. 2004. The Evolution of Corporate Social Responsibility in Japan (Part 1) Parallels with the History of Corporate Reform. NLI Research Institute. Tokyo, Japan.

Luck, C. and N. Pilotte. 1992. Domini Social Index Performance'. BARRA Newsletter, Nov/Dec.

Lincoln, Edward J. 2001. Time to End Postal Savings. Sentaku, June 2. http://www.brookings.edu/views/articles/lincoln/20010602.htm

Nishimura, K. and M. Saiko. 2003. On Alternatives to Aggressive Demand Policies to Revitalize the Japanese Economy. Asian Economic Papers. 2(3): 87-126.

Rudd, Andrew. 1981. Social Responsibility and Portfolio Performance, California Management Review, 23(4): 55-61.

Solomon, A., J. Solomon, and M. Suto. 2004, Can the UK Experience Provide Lessons for the Evolution of SRI in Japan? Corporate Governance. 12(4): 552-566.

Wood, K. 1992. Ethical Investment in the UK: The Barra/ ERIS study, BARRA Newsletter, March/April. 
Table 1. Stocks Included in Key Japanese SRI Indices

\begin{tabular}{lccc}
\hline \multicolumn{1}{c}{ INDICES } & STOCKS & \% of SRI stocks & TOP 10 STOCKS \\
\hline Morningstar SRI & 150 & $64 \%$ & 10 \\
FTSE4GOOD & 166 & $71 \%$ & 10 \\
In both indices & 83 & $36 \%$ & 8 \\
In at least one index & 233 & $100 \%$ & 12 \\
\hline $\begin{array}{l}\text { Source: Authors' computations based on data provided by FTSE4Good and Morningstar SRI Japan as of } \\
\text { September 2004. }\end{array}$
\end{tabular}




\section{Table 2. Top 10 Constituent Weights in FTSE4GOOD and Morningstar SRI Indices}

\begin{tabular}{|c|c|c|c|c|c|}
\hline $\begin{array}{c}\text { STOCK } \\
\text { CODE }\end{array}$ & NAME & $\begin{array}{l}\text { Weight in } \\
\text { FTSE }\end{array}$ & $\begin{array}{l}\text { Rank in } \\
\text { FTSE }\end{array}$ & $\begin{array}{l}\text { Weight in } \\
\text { Morningstar }\end{array}$ & $\begin{array}{c}\text { Rank in } \\
\text { MS }\end{array}$ \\
\hline 7751 & Canon Inc. & $4.40 \%$ & 2 & $3.43 \%$ & 5 \\
\hline 9437 & NTT DoCoMo,Inc. & $3.90 \%$ & 3 & $3.14 \%$ & 7 \\
\hline 6752 & Matsushita Electric Ind. & $3.50 \%$ & 5 & $2.90 \%$ & 8 \\
\hline 6758 & SONY Corp. & $3.30 \%$ & 6 & $3.19 \%$ & 6 \\
\hline 8316 & Sumitomo Mitsui Financial & $2.80 \%$ & 7 & $3.61 \%$ & 4 \\
\hline 7201 & Nissan Motor & $2.60 \%$ & 8 & $2.34 \%$ & 9 \\
\hline 9432 & NTT & $2.40 \%$ & 9 & $5.31 \%$ & 1 \\
\hline \multirow[t]{2}{*}{8766} & Millea Holdings,Inc. & $2.00 \%$ & 10 & $2.33 \%$ & 10 \\
\hline & Sub Total Weights of Common 8 in indices & $24.90 \%$ & & $26.24 \%$ & \\
\hline 7203 & Toyota Motor & $11.20 \%$ & 1 & $0 \%$ & \\
\hline \multirow[t]{2}{*}{7267} & Honda Motor & $3.80 \%$ & 4 & $0 \%$ & \\
\hline & Sub Total Weights of Special 2 in FTSE4GOOD & $15.00 \%$ & & & \\
\hline 8411 & Mizuho Financial Group,In & $0 \%$ & & $4.90 \%$ & 2 \\
\hline 4502 & Takeda Chemical Ind. & $0 \%$ & & $3.80 \%$ & 3 \\
\hline \multicolumn{3}{|c|}{ Sub Total Weights of Special 2 in Morningstar } & & $8.70 \%$ & \\
\hline & Total Weights of TOP 10 in Indices & $39.90 \%$ & & $34.94 \%$ & \\
\hline
\end{tabular}


Figure 1. Financial Performance of Major SRI Indices in Japan (1997 2005)

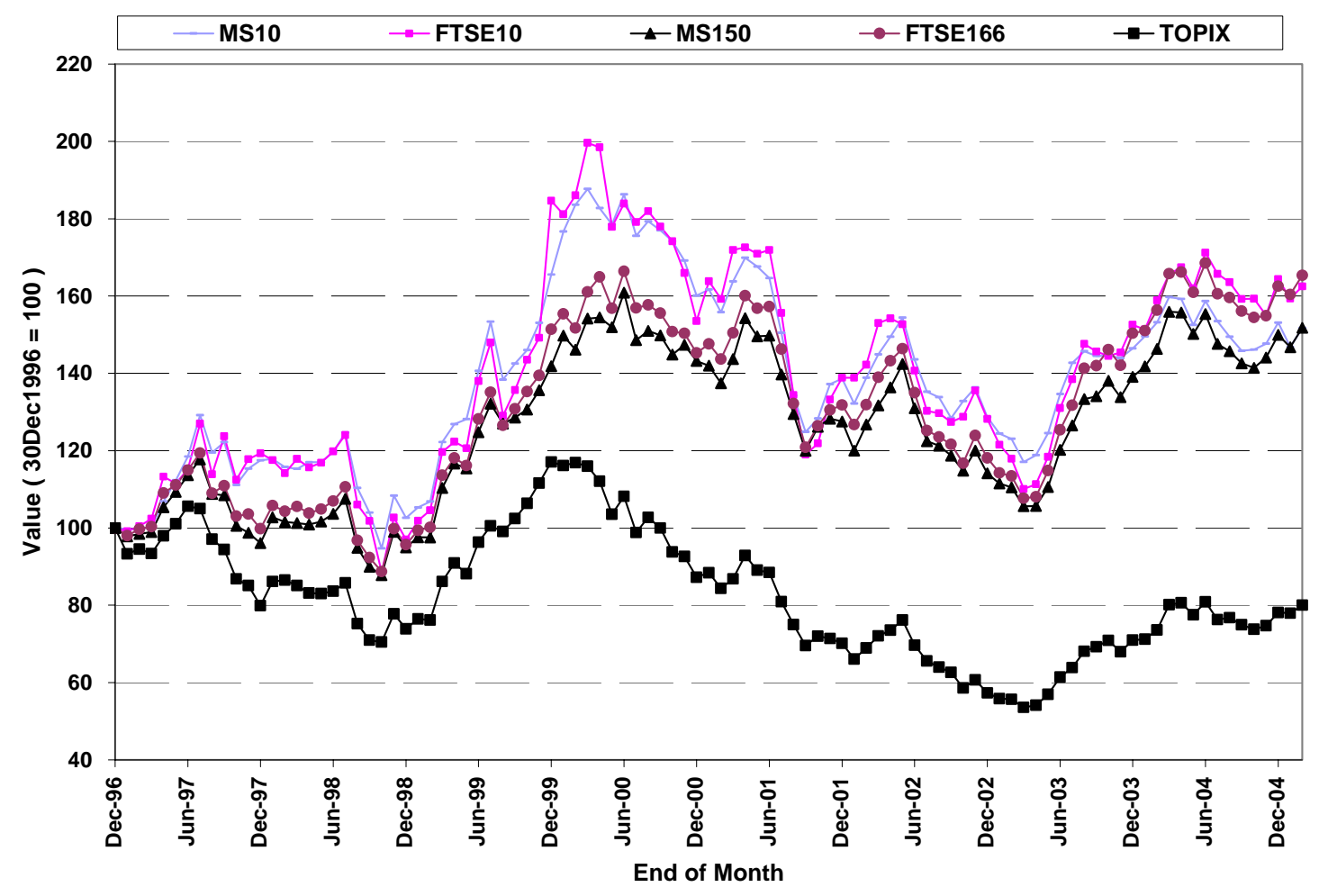

Sources: Authors' calculations based on data supplied by the Securities Industry Research Centre of Asia-Pacific (SIRCA) on behalf of Reuters. See Appendix A. 
Table 3. Retrospective Performance of Alternative Japanese SRI Index Funds (1997 2005)

\begin{tabular}{cccccc}
\hline Year & MS10 & F4G10 & MS150 & F4G166 & TOPIX \\
\hline 1997 & $17.50 \%$ & $19.30 \%$ & $-3.90 \%$ & $-0.20 \%$ & $-20.10 \%$ \\
1998 & $-12.70 \%$ & $-18.70 \%$ & $-1.10 \%$ & $-4.10 \%$ & $-7.50 \%$ \\
1999 & $61.40 \%$ & $90.30 \%$ & $49.30 \%$ & $58.20 \%$ & $58.40 \%$ \\
2000 & $-3.30 \%$ & $-16.80 \%$ & $1.00 \%$ & $-4.00 \%$ & $-25.50 \%$ \\
2001 & $-13.40 \%$ & $-9.60 \%$ & $-10.90 \%$ & $-9.30 \%$ & $-19.60 \%$ \\
2002 & $-7.20 \%$ & $-7.70 \%$ & $-10.50 \%$ & $-10.40 \%$ & $-18.30 \%$ \\
2003 & $13.80 \%$ & $19.00 \%$ & $21.90 \%$ & $27.30 \%$ & $23.80 \%$ \\
2004 & $4.50 \%$ & $7.80 \%$ & $7.80 \%$ & $8.10 \%$ & $10.20 \%$ \\
$2005 *$ & $-0.90 \%$ & $-1.20 \%$ & $1.20 \%$ & $1.70 \%$ & $2.40 \%$ \\
\hline TOTAL & $\mathbf{5 1 . 7 0 \%}$ & $\mathbf{6 2 . 5 0 \%}$ & $\mathbf{5 1 . 7 0 \%}$ & $\mathbf{6 5 . 3 0 \%}$ & $\mathbf{- 2 0 . 0 0 \%}$ \\
Annualized \% Return & $\mathbf{5 . 2 3 \%}$ & $\mathbf{6 . 1 2} \%$ & $\mathbf{5 . 2 4 \%}$ & $\mathbf{6 . 3 5 \%}$ & $\mathbf{- 2 . 6 9 \%}$ \\
Annualized \% Volatility & $\mathbf{1 7 . 6 0 \%}$ & $\mathbf{2 2 . 7 0 \%}$ & $\mathbf{1 6 . 0 0 \%}$ & $\mathbf{1 7 . 0 0 \%}$ & $\mathbf{1 7 . 0 0 \%}$ \\
Alpha** & $\mathbf{7 . 9 2 \%}$ & $\mathbf{1 0 . 1 6 \%}$ & $\mathbf{7 . 7 5 \%}$ & $\mathbf{9 . 1 3 \%}$ & $\mathbf{0 . 0 0 \%}$ \\
Beta & $\mathbf{0 . 8 2}$ & $\mathbf{0 . 9 6}$ & $\mathbf{0 . 8 8}$ & $\mathbf{0 . 9 2}$ & $\mathbf{1}$ \\
\hline
\end{tabular}

Sources: Authors' calculations based on data supplied by the Securities Industry Research Centre of Asia-Pacific (SIRCA) on behalf of Reuters). * There are only two months data for 2005. ** Alpha and Beta are annualized estimates of CAPM model with TOPIX as the benchmark. See also Appendix A. 
Figure 2. Retrospective Performance of SRI Indexes in Japan (1997 2005)

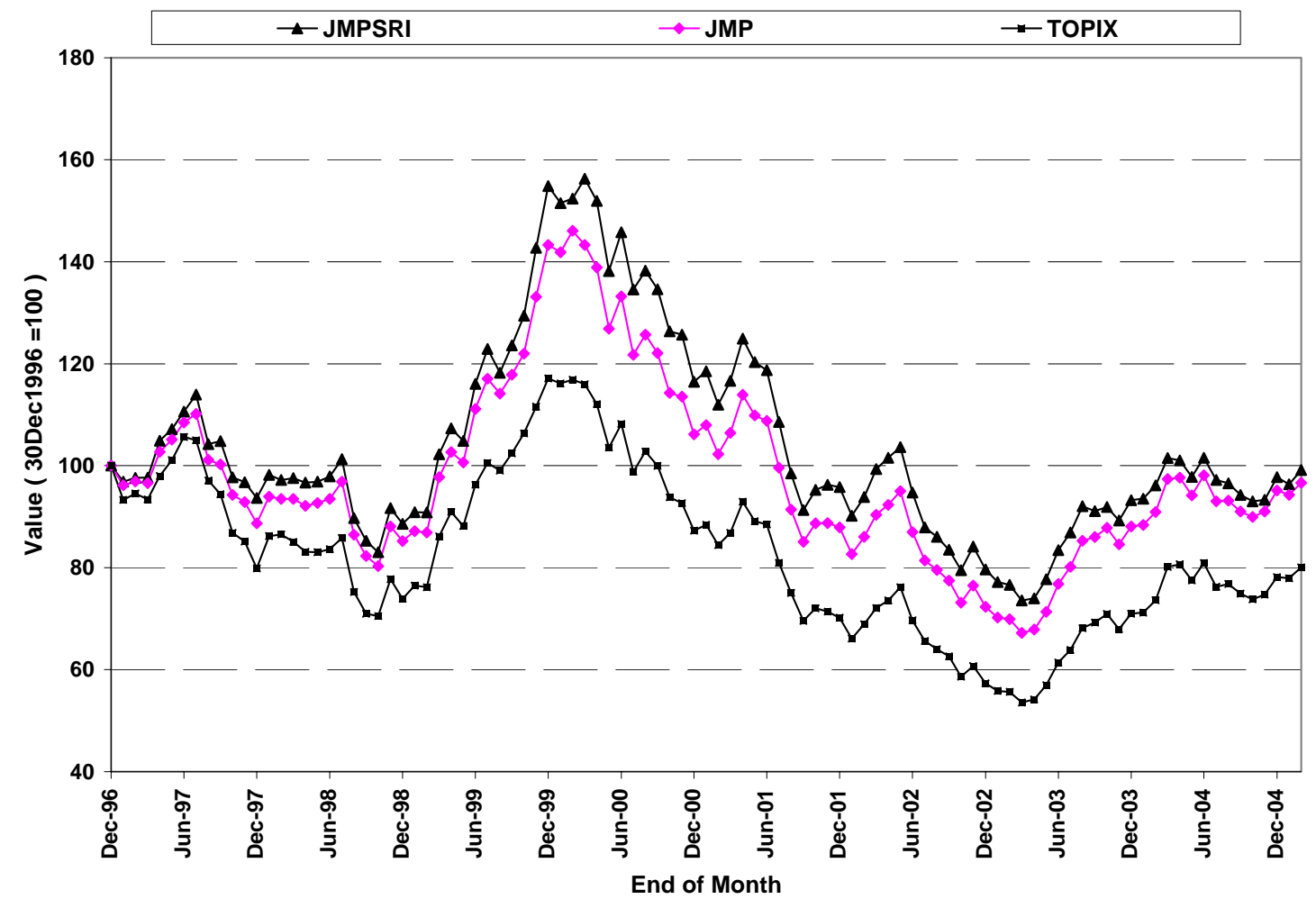

Source: Authors' calculations based on data supplied by the Securities Industry Research Centre of Asia-Pacific (SIRCA) on behalf of Reuters. See also Appendix A. 
Table 4. The Power of SRI in Japan 1997 2005: A Pre and Post Analysis

\begin{tabular}{|c|c|c|c|c|c|c|c|c|}
\hline \multirow{2}{*}{$\begin{array}{c}\text { Model } \\
\begin{array}{c}\text { Independent } \\
\text { Variables }\end{array}\end{array}$} & \multicolumn{2}{|c|}{ Model 1\# } & \multicolumn{2}{|c|}{ Model 2} & \multicolumn{2}{|c|}{ Model 3} & \multicolumn{2}{|c|}{ Model 4} \\
\hline & Pre $e^{* *}$ & Post & Pre & Post & Pre & Post & Pre & Post \\
\hline Intercept & $0.0039 *$ & $0.0081^{*}$ & $0.0016^{*}$ & $0.0075^{*}$ & $0.0039 *$ & $0.0065^{*}$ & $0.0016^{*}$ & $0.0059 *$ \\
\hline $\begin{array}{c}\text { Excess return of } \\
\text { JMP }\end{array}$ & $0.8342^{*}$ & $1.1568 *$ & $0.8311^{*}$ & 1.1538* & $0.8381 *$ & $1.2615^{*}$ & $0.8353 *$ & $1.2600^{*}$ \\
\hline SRI flag & 0.0004 & $-0.0063^{*}$ & 0.0018 & $-0.0050 *$ & 0.0004 & -0.0028 & 0.0018 & -0.0014 \\
\hline $\begin{array}{l}\text { SRI * Excess } \\
\text { return of JMP }\end{array}$ & & & & & -0.0084 & $-0.2312 *$ & -0.0090 & $-0.2345^{*}$ \\
\hline $\begin{array}{l}\text { Market Cap In } \\
\text { Trillion Yen }\end{array}$ & & & $-0.0023 *$ & $-0.0030 *$ & & & $-0.0024 *$ & $-0.0030 *$ \\
\hline $\begin{array}{c}\text { Price to Book } \\
\text { Value Ratio }\end{array}$ & & & $0.0013^{*}$ & $0.0006^{*}$ & & & $0.0013^{*}$ & $-0.0006 *$ \\
\hline $\begin{array}{l}\text { Adjusted R- } \\
\text { squared }\end{array}$ & 0.1194 & 0.1441 & 0.1219 & 0.1481 & 0.1193 & 0.1454 & 0.1219 & 0.1495 \\
\hline $\begin{array}{c}\text { Number of } \\
\text { Observations }\end{array}$ & 40,920 & 11,823 & 40,920 & 11,823 & 40,920 & 11,823 & 40,920 & 11,823 \\
\hline
\end{tabular}

Source: Authors' calculations based on data supplied by the Securities Industry Research Centre of Asia-Pacific (SIRCA) on behalf of Reuters.

\# Model 1 is an OLS regression of the monthly excess returns of each stock in JMP against the excess returns of JMP index and a stock-specific SRI flag; Model 2 adds an additional risk control of big/small cap bias and value/growth style bias; Model 3 adds an interaction term between SRI flag and excess return of JMP; Model 4 combines Models 2 and 3.

* indicates the parameter estimation is statistically significant at the 0.05 level.

***Pre refers to the 77 months of the sample period prior to the formal launch of SRI indices in Japan (Jan 1997 to May 2003); Post stands for the rest of the sample period from June 2003 to Feb 2005 for a total of 21 months. 
Appendix A. Pre And Post Evaluation of SRI Performance in Japan (1997 2005) With Alternative Benchmarks

\begin{tabular}{|c|c|c|c|c|c|c|c|c|c|}
\hline & MS10 & F4G10 & MS150 & F4G166 & TOPIX & JMP & JMPSRI & JMP_E & JMPSRI_E \\
\hline Annual \% Return & $5.23 \%$ & $6.12 \%$ & $5.24 \%$ & $6.35 \%$ & $-2.69 \%$ & $-0.42 \%$ & $-0.11 \%$ & $5.59 \%$ & $5.16 \%$ \\
\hline pre-launch & $3.47 \%$ & $2.67 \%$ & $1.58 \%$ & $2.18 \%$ & $-8.40 \%$ & $-5.13 \%$ & $-3.85 \%$ & $-0.18 \%$ & $0.34 \%$ \\
\hline post-launch & $11.94 \%$ & $19.83 \%$ & $19.81 \%$ & $23.15 \%$ & $21.47 \%$ & $18.95 \%$ & $14.91 \%$ & $29.76 \%$ & $24.88 \%$ \\
\hline Annualized \% Volatility & $17.57 \%$ & $22.72 \%$ & $16.05 \%$ & $17.02 \%$ & $16.97 \%$ & $16.76 \%$ & $17.22 \%$ & $18.19 \%$ & $17.09 \%$ \\
\hline pre-launch & $18.94 \%$ & $24.57 \%$ & $16.81 \%$ & $17.84 \%$ & $17.49 \%$ & $17.58 \%$ & $18.36 \%$ & $18.77 \%$ & $17.87 \%$ \\
\hline post-launch & $11.46 \%$ & $14.01 \%$ & $12.56 \%$ & $13.17 \%$ & $13.49 \%$ & $12.46 \%$ & $11.72 \%$ & $14.85 \%$ & $13.11 \%$ \\
\hline \multicolumn{10}{|c|}{ TOPIX AS BENCHMARK } \\
\hline Alpha & $0.64 \%$ & $0.81 \%$ & $0.62 \%$ & $0.73 \%$ & $0.00 \%$ & $0.18 \%$ & $0.22 \%$ & $0.69 \%$ & $0.63 \%$ \\
\hline pre-launch & $0.95 \%$ & $1.07 \%$ & $0.78 \%$ & $0.87 \%$ & $0.00 \%$ & $0.28 \%$ & $0.42 \%$ & $0.68 \%$ & $0.70 \%$ \\
\hline post-launch & $-0.17 \%$ & $0.16 \%$ & $0.06 \%$ & $0.22 \%$ & $0.00 \%$ & $-0.05 \%$ & $-0.20 \%$ & $0.44 \%$ & $0.30 \%$ \\
\hline Beta & 0.82 & 0.96 & 0.88 & 0.92 & 1.00 & 0.97 & 0.97 & 0.97 & 0.97 \\
\hline pre-launch & 0.87 & 1.00 & 0.89 & 0.93 & 1.00 & 0.98 & 1.01 & 0.92 & 0.90 \\
\hline post-launch & 0.68 & 0.84 & 0.89 & 0.94 & 1.00 & 0.92 & 0.83 & 1.08 & 0.96 \\
\hline \multicolumn{10}{|c|}{ JMP AS BENCHMARK } \\
\hline Alpha & $0.48 \%$ & $0.62 \%$ & $0.46 \%$ & $0.56 \%$ & $-0.19 \%$ & $0.00 \%$ & $0.03 \%$ & $0.52 \%$ & $0.47 \%$ \\
\hline pre-launch & $0.71 \%$ & $0.81 \%$ & $0.51 \%$ & $0.60 \%$ & $-0.30 \%$ & $0.00 \%$ & $0.13 \%$ & $0.38 \%$ & $0.41 \%$ \\
\hline post-launch & $-0.18 \%$ & $0.14 \%$ & $0.09 \%$ & $0.24 \%$ & $0.07 \%$ & $0.00 \%$ & $-0.18 \%$ & $0.53 \%$ & $0.37 \%$ \\
\hline Beta & 0.88 & 1.06 & 0.88 & 0.94 & 0.99 & 1.00 & 1.01 & 0.88 & 0.86 \\
\hline pre-launch & 0.91 & 1.09 & 0.87 & 0.93 & 0.97 & 1.00 & 1.03 & 0.84 & 0.83 \\
\hline post-launch & 0.78 & 0.96 & 0.98 & 1.04 & 1.08 & 1.00 & 0.92 & 1.16 & 1.03 \\
\hline
\end{tabular}

Sources: Authors' calculations based on data supplied by the Securities Industry Research Centre of Asia-Pacific (SIRCA) on behalf of Reuters over the 98 month period up to Feb 2005. A top-10 and a full index portfolio were constructed respectively for Morningstar SRI Japan (MS) and FTSE4GOOD Japan (F4G) according to their launching weights as of May 2003 and Sep 2004. The portfolios were then rebalanced monthly using their initial weights. Some of the stocks were not listed over the whole period of study, so their weights were shared by other stocks accordingly. JMP stands for a hypothetical portfolio constructed by the authors as a representation of the Japanese stock investment universe; it contains 563 stocks and is weighted by market cap and rebalanced monthly. The portfolio comprises all stocks in the NK500 index, the FTSE Japan index, and the Morningstar SRI index as of Sep 2004 (as long as there were at least 24 monthly return observations over the period). The rationale for the JMP portfolio is to control for survivorship and new company bias. JMP SRI is the SRI subset of JMP index containing 233 SRI stocks, either from MS150 or F4G166. This combined SRI portfolio was rebalanced monthly using market capitalization. JMP_E and JMPSRI_E are equally weighted JMP and JMPSRI portfolios. They are included in our study to have a control of big cap bias. Dividends are not included in the comparison, since an accumulation TOPIX did not exist until June 2001. Alpha and Beta are monthly estimates of the CAPM model. Pre-launch refers to the 77 months of the sample period prior to the formal launch of SRI indices in Japan (Jan 1997 to May 2003); Post-launch stands for the rest of the sample period from June 2003 to Feb 2005 for a total of 21 months. 